\title{
43. Data Journalism, Digital Universalism and Innovation in the Periphery
}

\author{
Anita Say Chan
}

\begin{abstract}
The "myth of digital universalism" manifests not only in the means by which it keeps public narratives and imaginations fixed exclusively around so-called "centres" of innovation, but in the means by which it simultaneously discourages attention to digital dynamics beyond such centres-a dynamic conjuring colonial relations to data and the periphery that reporters and scholars of global digital cultures alike must be wary of reproducing.
\end{abstract}

Keywords: digital universalism, centre, periphery, colonial relations, decolonial computing, local innovation

"Digital universalism" is the pervasive but mistaken framework shaping global imaginaries around the digital that presumes that a single, universal narrative propelled by "centres" of innovation can accurately represent the forms of digital development underway across the globe today. It presumes, that is, that the given centres of contemporary "innovation" and technological design will inevitably determine the digital future that comes to spread across the world for the majority of the "digital rest." And it resonates through the casual presumption that the best, most "legitimate" sites from which to study and observe technological transformation, digital productivity and practice, or information-based innovation and inquiry, are from such centres. Foremost among them: The labs, offices and research sites nestled in Silicon Valley and their dispersed equivalents in other innovation capitals worldwide that concentrate elite forms of digital expertise.

It is from such centres that digital culture presumably originates and has its purest form and manifestation—only to be replicated elsewhere; there

Bounegru, L. and J. Gray (eds.), The Data Journalism Handbook: Towards a Critical Data Practice. Amsterdam: Amsterdam University Press, 2021 DOI 10.5117/9789462989511_CH43 
that visions for digital futuricity in its most accurate or ideal approximations emerge; and there that technological advancements — and thus digital cultural advancements - are dominantly understood to be at their most dynamic, lively and inspired. It assumes, in other words, that digital culture-despite its uniquely global dimensions_-does indeed have more "authentic" and productive sites from which to undertake its study and observe its dynamics.

As a young researcher studying and writing about digital cultural activism and policy in Peru and Latin America from the early 200os onward, it shaped my experience in fundamental ways, most regularly in the routine and seemingly innocent question I heard: "Why go to Peru or Latin America to study digital culture?" Weren't there "better" sites from which to study digital cultures, and wouldn't my time be better invested attending to and documenting activity in a site like Silicon Valley?

For such questioners, Peru inevitably evoked the idea of a mountainous South American nation that once served as the heart of the Inca civilization: Home to Machu Picchu, high stretches of the Andes mountain range, and large populations of Quechua- and Aymara-speaking communities. This Peru might be known as an ideal space from which to peer into past tradition, native culture or the plethora of nature's bounty-but it had little to tell us, the thinking went, about the dynamics of contemporary digital culture, high technological flows or their associated future-oriented developments. Places such as Peru might unlock a path strewn with the relics and treasures of a technological past we'd have to literally struggle not to forget, while sites like Silicon Valley are where the secrets to a technological future whose path we had yet to fully tread would inevitably come to be unlocked.

Quietly asserted in such a question then, is a casual certainty around the idea that the digital futures imagined by select populations of technologists in elite design centres can speak for the global rest, and the present currently unfolding in innovation centres must surely be the future of the periphery.

The power of the "myth of digital universalism" thus manifests not only in the means by which it keeps public narratives and imaginations fixed exclusively around established centres of innovation, but in the means by which it simultaneously discourages attention to digital dynamics beyond such centres. It therein narrows the diversity and global circulation of narratives around actual digital dynamics occurring across a range of locales, invisibilizes diverse forms of digital generativity, and artificially amplifies and reinforces a representation of "innovation" capitals as exclusive sites of digital productivity.

There is a particular colonial notion of the periphery conjured here that reporters and scholars of global digital cultures alike must be wary of 
reproducing: That is, of the "periphery" as mere agents of global counterfeit or zones of diffusion for a future invented prior and elsewhere. Indeed, the periphery is hardly so passive or uninventive. Lively and dynamic outdoor markets or Internet cafes filled with used, recycled and reassembled computers and parts are innovations of the Global South that extended low-cost Internet access and scaled out global and local media content circulation to diverse populations in rural and urban zones alike. These technological hacks and local improvisations are an everyday part of the periphery's technology landscape whose vibrancy is only partly captured by comparing it to formalized commercial chains of digital goods or computer and Internet suppliers. As the social scientists Daniel Miller and Don Slater (2001) observed in their study of Trinidad, "the Internet is not a monolithic cyberspace," but exists instead as a globally expansive technology with various local realities, adoptive practices and cultural politics that surround its varying localizations. There have been, indeed, more ways than one to imagine what digital practice and connection could look like.

In Peru, evidence of lively digital cultures that brought a range of distinct actors and interests into unexpected and often contradictory proximity was readily visible. Apparent collectives of free software advocates, who had helped to bring the first $\mathrm{UN}$-sponsored conference on free software use in Latin America — a landmark event - to the ancient Incan capital of Cuzco in 2003, sought to reframe the adoption of open technologies. They sought to reframe it as not just an issue of individual liberty and free choice, as it had been for free/libre and open-source software (FLOSS) advocacy in the United States, but of cultural diversity, state transparency and political sovereignty from the monopolistic power of transnational corporations in the Global South.

"Digital innovation" classrooms installed in rural schools by the state would later be converted into the largest network of deployment sites for MIT's high-profile One Laptop per Child (OLPC) initiative just several years later, all in the name of enabling universal digital inclusion. And intellectual property (IP) titles newly and aggressively applied by state programmes to "traditional" goods promised to convert rural producers and artisans into new classes of export-ready "information workers" as part of the nation's growing information society-based initiatives.

FLOSS advocates and high-tech activists in Cuzco, state-promoted "innovation classrooms" in rural schools, and traditional artisans as new global "information workers" were not the conventional interests or protagonists that emerged from most tales spun in centres of digital culture. To watch their stories unfold was to watch the details of each spill over the edges of the existing frameworks and dominant narratives of digital culture. Global 
imaginaries around IT in the new millennium, after all, have made Silicon Valley hackers, the obsessions and aspirations of high-tech engineers, and the strategic enterprise of competitive technology entrepreneurs, the stuff of popular Hollywood films and obsessively followed Twitter accounts. These are a cast of increasingly recognizable actors, heroes and villains. But to capture the dynamic engagements and fraught experiments in digital culture in Peru requires attention to a host of other stakes, agents and developments - ones that in working around the digital tried to build new links and exchanges between spaces of the rural and the urban, the high-tech and the traditional, and distinct orientations around the global with intensive commitments to the local.

Data journalists today have a growing host of digital tools and technological resources to witness, capture and recall digital cultures and activities across a range of local sites around the world. Even before the wave of social protests in the Middle East starting in early 2011, networked digital media extended new global broadcast capabilities for movements that adopted strategic uses of social media in contexts as diverse as Mexico (Schulz, 2007), Iran (Burns \& Eltham, 2009; Grossman, 2009), the Philippines (Uy-Tioco, 2003; Vicente, 2003) and Ukraine (Morozov, 2010).

In the wake of the 2011 Arab Spring-movements from Spain's 15-M Indignados, to the North American Occupy, made strategic uses of hashtag organizing and activism on social media platforms. More recently, movements from the US-launched \#MeToo and \#BlackLivesMatter run alongside global mobilizations from Latin America's \#NiUnaMenos, to the Nigerianlaunched \#BringBackOurGirls, Australia's \#Sosblakaustralia, Canadian First Nations' \#IdleNoMore mobilizations and Hong Kong's \#UmbrellaRevolution.

Such movements' expanding user-generated media streams multiply civic data practices and decentre the dominant applications of "big data" on social media platforms that bias towards forms of market-oriented profiling. They instead leverage data practices for new forms of narrative capacity that break from established centres of media and news production while lending their data archives - and online evidence of the global extensions of their publics - to geographically dispersed documentarians, reporters and organizers alike.

But the growth of digital resources and data repositories - from online "data" archives by social movements on social media platforms, to parallel forms of creative data activism - creates new risks for data journalists as well. Foremost among these is a risk from the seductive capacity of big data and social media platforms to leverage the abundance of data and information they collect as a means to convince audiences that their extensive data 
trackings compile and create the best possible form of documenting present human activity and social experience — as well as assessing and predicting the future of their political or economic ramifications.

The temporal presumptiveness of digital universalists' projection that the forms of digital "present" cultivated in innovation centres today can and will accurately represent the digital futures of global peripheries finds a new complement in data industries' self-assured claims for the predictive capacities of algorithmic data processing. Such pronouncements remain, even despite the evident contemporary failures of mainstream political data analysts, social media companies and news pundits in the West to accurately predict the major global political disruptions of recent years-from the 2016 US presidential election, to Brexit, to the Cambridge Analytica scandal, to the "surprise" rise of the alt-right movements across the West.

Today's data journalists should be vigilantly wary of enabling data tracings and archives - regardless of how extensive and impressively large they may be- to serve as the sole or dominant form of documenting, speaking for and assessing the diverse forms of social realities that the public relies on them to channel. Parallel with growing calls from Latin American and postcolonial scholars for broadening research and documentation methods to expand what and who represents information, technology and new media cultures under a "decolonial computing" framework (Chan, 2018), data journalists critical of digital universalist frameworks should aim too to consciously diversify data sources and decentre methods that would privilege "big data" as the exclusive or most legitimate key to mapping empirical events and social realities. Moves towards a "decolonization of knowledge" underscore the significance of the diverse ways through which citizens and researchers in the Global South are engaging in bottom-up data practices. ${ }^{1}$ These practices leverage an emphasis on community practices and human-centred means of assessing and interpreting data - for social change, as well as speaking for the resistances to uses of big data that increase oppression, inequality and social harm.

Data journalists critical of digital universalism's new extensions in data universalism should take heart to find allies and resonant concerns for developing accountable and responsible data practices with scholars in critical data studies, algorithm studies, software and platform studies, and postcolonial computing. This includes a reinforced rejection of data fundamentalism (Boyd \& Crawford, 2012) and technological determinism that still surrounds mainstream accounts of algorithms in application. It also entails a fundamental recentring of the human within datafied worlds and data 
industries - that resists the urge to read big data and "algorithms as fetishized objects ... and firmly resist[s] putting the technology in the explanatory driver's seat" (Crawford, 2016). It also involves treating data infrastructures and the underlying algorithms that give political life to them intentionally as both ambiguous and approachable - to develop methodologies that not only explore new empirical and everyday settings for data politics - whether airport security, credit scoring, hospital and patient tracking, or social media across a diversity of global sites - but also find creative ways to make data productive for analysis (Gillespie, 2013; Ziewitz, 2016).

Finally, it is perhaps worth a reminder that conserving the given centres of digital innovation as the exclusive sites of digital invention or the making of data futures, of course, also neglects another crucial detail-that the centres of the present were once on the periphery, too. To focus on centres as inventing models that simply come to be adopted and copied elsewhere presumes the perfect, continual extension of replicative functions and forces. It fails to account for the possibility of change within the larger system - the destabilizations and realignments of prior centres-and so, too, the realignments of prior peripheries.

The "surprise" of the 2011 Arab Spring and its influence across a range of global sites in the West and non-West like, much like the recent rise of non-Western digital markets and economic competitors in nations labelled "developing" less than two decades ago, and the destabilization of powerful Western democracies today, are reminders that the stability of established powers and the permanence of centre-periphery relations can questioned. Far from merely lagging behind or mimicking centres, dynamic activities from the periphery suggest how agents once holding minor status can emerge instead as fresh sources of distinct productivity. Their diverse threads unsettle the unspoken presumption that a single, universal narrative could adequately represent the distinct digital futures and imaginaries emerging across a range of local sites today.

\section{Works Cited}

Boyd, D., \& Crawford, K. (2012). Critical questions for big data. Information, Communication \& Society, 15(5), 662-679. https://doi.org/10.1080/1369118X.2012.678878

Burns, A., \& Eltham, B. (2009). Twitter free Iran: An evaluation of Twitter's role in public diplomacy and information operations in Iran's 2009 election crisis. In P. Franco \& M. Armstrong (Eds.), Record of the Communications Policy \& Research Forum 2009 (pp. 322-334). Network Insight Institute. 
Chan, A. (2018). Decolonial computing and networking beyond digital universalism. Catalyst, 4(2). https://doi.org/10.28968/cftt.v4i2.29844

Crawford, K. (2016). Can an algorithm be agonistic? Ten scenes from life in calculated publics. Science, Technology, \& Human Values, 41(1), 77-92. https://doi. org/10.1177/0162243915589635

Gillespie, T. (2013). The relevance of algorithms. In T. Gillespie, P. J. Boczkowski, \& K. A. Foot (Eds.), Media technologies: Essays on communication, materiality, and society (pp. 167-193). MIT Press.

Grossman, L. (2009, June 17). Iran's protests: Why Twitter is the medium of the movement. Time. http://content.time.com/time/world/article/o,8599,1905125,00. html

Miller, D., \& Slater, D. (2001). The Internet: An ethnographic approach. Berg Publishers. Morozov, E. (2010). The net delusion: The dark side of Internet freedom. Public Affairs. Schulz, M. (2007). The role of the Internet in transnational mobilization: A case study of the Zapatista movement, 1994-2005. In M. Herkenrath (Ed.), Civil society: Local and regional responses to global challenges (pp. 129-156). Transaction Publishers.

Uy-Tioco, C. (2003, October 11). The cell phone and EDSA 2: The role of a communication technology in ousting a president. Critical Themes in Media Studies Conference.

Vicente, R. (2003). The cell phone and the crowd: Messianic politics in the contemporary Philippines. Public Culture, 24(47), 3-36. https://doi.org/10.1080/o11 54451.2003.9754246

Ziewitz, M. (2016). Governing algorithms: Myth, mess, and methods. Science, Technology, \& Human Values, 41(1), 3-16. https://doi.org/10.1177/0162243915608948

\section{About the Author}

Anita Say Chan is Associate Professor at the School of Information Sciences and College of Media, and Faculty Fellow at the National Center for Supercomputing Applications at the University of Illinois, Urbana-Champaign, and Faculty Fellow at the Data \& Society Research Institute in New York. 